\title{
Youth Outdoor Feature Requirements in Urban Public Low-cost Housing
}

\author{
Kamarul Ariff Omar*, Dasimah Omar, \\ Saberi Othman, Zaharah Mohd Yusoff \\ Faculty of Architecture, Planning and Surveying \\ Universiti Teknologi Mara, Shah Alam, Selangor, Malaysia \\ ariff_nia@yahoo.com
}

\begin{abstract}
Youth is part of the community consent contributors. They are the energetic potency in fulfilling the social program and physical planning development. They are described as an active group in the community. The previous studies showed that youth shapes the pattern of lifestyle in neighbourhood units and even the nation itself. This paper will focus on the low-cost housing areas in which is high density and with scarce spaces as the existing facilities did not appear to attract youth's intention and even for their uses. As a result, reviewing the youth service requirements can enhance youth's quality of life.
\end{abstract}

Keywords: Community Empowerment; Low-Cost Housing; Youth Facilities; Quality of Life

eISSN 2398-4279 @ 2018. The Authors. Published for AMER ABRA cE-Bs by e-International Publishing House, Ltd., UK. This is an open access article under the CC BY-NC-ND license (http://creativecommons.org/licenses/bync-nd/4.0/). Peer-review under responsibility of AMER (Association of Malaysian Environment-Behaviour Researchers), ABRA (Association of Behavioural Researchers on Asians) and cE-Bs (Centre for EnvironmentBehaviour Studies), Faculty of Architecture, Planning \& Surveying, Universiti Teknologi MARA, Malaysia.

DOI: https://doi.org/10.21834/ajqol.v3i10.115 


\subsection{Introduction}

Housing is a primary production in the history of human development. Revolution in housing construction has progressed from times to times with various implementation and ideas. Housing starts as a necessity human need; the house has amplified to become as a profitable investment at present. The scenario has led to the several of construction housing schemes and given more option for public to buy it (Hashim, et. al, 2012b). Along with that, the provision of facilities such as community facilities, recreational facilities, and infrastructure apparently plays the role in determining the value of the housing unit.

Malaysia has implemented various policies that highlight the welfare of housing for the low-income employees to earn an affordable house (DRN or National Housing Policies). Some of the low-cost housing units were built in Kuala Lumpur City Centre, Lembah Pantai, Kerinchi, Bandar Tun Abdul Razak, and Cheras area has more low-cost housing neighbourhood (Housing Management \& Community Development Department, Kuala Lumpur City Hall, DBKL). According to Shuid (2010), these low-cost housing is affordable for lower income people outline by National Housing Policies as 78,000 units of low-cost housing will be built for this low-income people.

This paper aims to review the youth facility requirements in the urban public low-cost housing. This requirement covers various aspects and observers in providing necessary facilities for youth social interaction, and physical activity is healthy. The absent of spaces in the low-cost housing environment is a major issue in failure to provide social facilities to youth. Thus, the objective of this paper is to determine theoretically, the key requirements for the provision of youth facilities in low-cost housing environment. The second objective is to provide comments and suggestions to improve the quality of life for youth in low-cost housing based on facilities for social interaction and healthy physical activity.

\subsection{Literature Review}

Low-cost housing or Public Housing is known as affordable housing has recognized as the idea of the household need due to the insufficient incomes allowing them to access suitable home without any support from other peoples (Milligan, 2004). Low- cost housing is an example of affordable housing for lower income people in Malaysia. As the housing is important for people, Malaysia's government has taken the initial program to bring forward more low-cost housing schemes to improve the quality of life and creates comfortable and appropriate living environment for these lower income families (Hashim et al. 2012).

This housing scheme is a comprehensive effort by the government to address the issue of low-income group. Unfortunately often raises two main issues, at first which are the problem of construction of low-cost houses and low-cost housing problems (Johnston \& Neill, 2008). Hence, these problems cause various difficulties in the construction and preparation especially on public housing schemes as the government and developers need to provide sufficient facility within adequate spaces between affordable price range.

\section{Youth Facility for Outdoor Activities.}

Public affordable housing schemes provided by the Malaysian government has included with 
appropriate facilities such as the community hall, playground area, car parking, recreational compound, and commercial outlet (Karim, 2012b). These adequate facilities are currently used by everyone in the neighbourhood without any comparison and tolerance. This lowincome group has to access comfortable living quality in difficulty. Meanwhile, those facilities are not sufficient to entertain the entire neighbourhood, especially youth community. The availability of facilities in community environment influences the residents' quality of life. Even the facilities are available; youth community did not have sufficient space and time to entertain themselves in social activities and interaction (Crean, 2012). The population projection shows that Malaysia's population will be 30.5 million by 2015 , with average of $1.3 \%$ Growth per annum and it will achieve to $68.8 \%$ for $15-64$ years of the population in 2015 (Malaysia Statistic Department, 2015).

This group of ages includes the youth community whom will be undeniably live in the lowcost housing either with family or friends. Therefore, low-cost housing facility, especially for youth, needs to be review and updated coherent with the growth of youth in Malaysia.

Recreational Park such as neighbourhood parks, sports complexes and, community parks are the best place where people engage in physical activity; those areas must be conducive and encourage the residents in social interaction and physical activities (Danis et al., 2014). Most of the facilities were meant to be used by the children, oldies, and does not specialize for the youth.

Youth and space are commonly related to each other. However, this community often perceived to be 'troublemaker' among the society (Malone, 2002). Therefore, providing spaces for them will increase many problems (Norris \& Armstrong, 1999). (Bauman, 1998) Defined this youth as 'flawed consumer' who need to be removed as they threats to others in public space.

Youths are the pillars of society and the successor generation. They have a remarkable effort given regarding energy; they are unyielding and capabilities far enough for them to build strength. Also, youths often act by the way of comfortable thinking in such of imbalance community as the valuation basis is attributed to economic progress alone ("Journal of Youth Development," 2011).

Neighbourhood is a mechanism to drive the livelihood activities. This environment forces the community to affect the development of their children and youth characters (Narayan et al., 2002). It means that the well-being of people is categorized on how much they interact within the neighbourhood spaces. Relating this to youth and space marginalised; the minimal exposed to neighbourhood space by the youth decrease their characters and skills development.

\subsection{Methodology}

This research has been carried out using the meta-synthesis technique as the related studies from the previous authors are integrated, evaluate and interpret. This method has an interpretive, rather than aiming and comparing of quantitative studies. The aim is to increase the understanding at the conclusion by explaining the relativity among several studies using knowledge generation. Thus, the synthesis analysis comparatively transforms the findings of 
qualitative data into the comprehensive understanding or explanatory hypothesis.

At the first stage, the researchers develop a theoretical framework based on the previous article and journal related to the research topic. The criteria mention in this framework is interpreted in defining the best requirement for youth facilities in the low-cost housing area. At the final stage, those criteria are linkage with the previous study to derive the relationship between facility requirements and youth QOL. Thus, the requirements are acceptance for Malaysia Public Housing Project only because the Housing Policy in Malaysia still needs to be refurbishment with better guideline and standards of quality of life (QOL).

\subsection{Findings and Discussions}

The physical environment is important for youth QOL. Providing outdoor facilities for outdoor activities will increase human activeness. Outdoor activity and physical environment have been connected to the health of humans since ancient times. However, human life in this century is much different when compared to the beginning of human life. The industrial revolution has led to dramatic changes in human lifestyle. Human dependence on technology is increasing all the time causes the least human involvement in work-related physical activity (Heyward, 2011). Youth is the group that is mostly stunned with these technological changes; they are likely to enjoy this technology because it is more easily too achieved and owned. In the same context, the failure of youth to enjoy social interaction physically openly in public places is due to the absence instrument that will entice them to do so (Yusop \& Sumari, 2013).

Based on the previous study, the improvements in current technology have shortened the limit on human recreation. We overlooked concerning the basic fundamental social play and interact with each other, namely 'availability' of space and facility instruments. Improvising the quality of life of residents, especially in low-cost housing, the 'availability' of community facilities is one of the factors that will influence their QOL index (Karim, 2011). The 'availability' of facility instruments especially on youth facility is critical to attracting youth in social activities and get interacting with each other in a limited space in such of low-cost housing environment. Within these facilities, it will figure out an attraction to the youth in having physical activity and social interaction.

'Accessibility' refers to the degree of reaching another point, i.e. the ability of a person to go to a destination either for the purpose of employment, education; business or getting other services (Chiarazzo et al., 2014). The accessibility measurement approaches associated with the opportunities available to an individual to reach the destination or chosen a location for a particular purpose correctly, quickly and safely with the availability of route and pathway. (Keles, 2011) Mention that access to institutions and public service is one of the characteristics in the quality of life (QOL) concept. Therefore, to improve the quality of life for youth in low-cost housing, this accessibility needs to verify as a guide when designing and developing those facilities.

'Proximity' is one way to achieve accessibility a facility and encourage the youths to access these facilities (Al-hagla, 2008). This is because, youth are categorized as a group who cannot afford for mobility rather than an adult, and the only way to move is by walking 
or using public transport (Rainham et al., 2012). Hence, proximity in every facility allocation might influence the youth for physical activities and social interaction.

Safety is an important issue in people's lives regardless of whether in urban or rural areas. Measuring the 'safety' aspects is often used by researchers as a factor to describe the quality of life (QOL) in neighbourhood living condition (Husin et al., 2015). In providing facilities for the community, 'safety' factor should be prioritized primarily in a low-cost housing area that is vulnerable to various threats and hazards (Kożuch \& Sienkiewicz-Małyjurek, 2014). Youth seems to be careless while using the facility; they were busy having social activities and interaction with the friend till negligent against their safety. The awareness of this safety factor must be understood by both designers and policy makers in the development of future urban housing as they contribute to improving people's quality of life (Okunola \& Amole, 2012).

'Social interaction' appears somehow in between of people and technology in a place one might call the social interface (Rachmamarcillia \& Ohno, 2006). The interaction of human behavioural and physical development is not just about the people and applications, but also human to human that allocate the social networking and communication while enjoying those facilities. The opportunity to create social interaction is a fundamental requirement for establishing a better quality of life (Hashim, 2012).

Therefore, in providing youth facilities, the need for social interaction will increase their desire to enjoy the facilities provided. This facility should be open and accessible for the purpose of open interaction. This can reduce the problem of the virtual mixing use of technology such as 'WhatsApp', 'facebook', and 'Wechat', youth will have the better living condition and social activities in limited space of low-cost housing environment.

As a result, these requirements merely define the basis on making facilities functional and meet the criteria for users. As youth is very vulnerable to its' surrounding, it is important to manage our physical environment wisely and purposely. Therefore, defining base requirements on developing outdoor facilities for youth in low-cost housing is elementary and mandatory because; youth need more space and supportive instrument in shaping their characters and self-skills.

\section{Conclusion}

Providing facilities in residential areas should be considering various aspect and guideline in order to deliver its functionality. This paper has revealed some of the requirement keys for youth facilities in Malaysia's low-cost housing, as it is able to create a better living space for youth. The outdoor facility in housing space, such low-cost neighbourhood area is important to develop more social interaction along with physical activities, especially for youth. The ability to meet the need of good QOL should not be abandon by the community of the residence, Governments' agency, and most important the youths themselves. The 'availability' aspect is the main requirement for ensuring a comfortable living environment for youth as the facilities are available and sufficient for them to enjoy it.

Even though Malaysia has a various agency for making this facilities reliable, people should take part in every decision-making process conducted by the local authorities in giving the best opinion and participate in every public programme to ensure this youth community is not marginalized in our limited space of low-cost housing environment. This action led to 
the proposition of 'accessibility' aspect of those facilities. By using the low-cost housing community and stakeholder participation, it with boost up the appropriate planning design to include the accessible path and reachable element.

Although focusing on the availability and accessibility, the compatibility of space should be appointed to create 'social interaction' among the user. Youth is the very active person in most of their activities that space must be suitable for them to make interaction. There are many planning guidelines that been implemented for many years ago, but the 'social interaction' is not listed as the main requirement for designing the facility in the low-cost housing.

Finally, beyond these entire factors require, most important in all services development is 'safety.' Within this appropriate safety factor, the outdoor facilities in the low-cost urban housing neighbourhood are rather limited for youth use. As the average age of youth in Malaysia is 15-40, it is important to understand that only youth between $15-25$ years old is only active in using the facilities provided. This age is likely vulnerable to be the victim of any threats. As low-cost housing still depended on natural surveillance from other residents in monitoring the safety of their property, providing the facilities with security aspect will increase the outdoor activities and improve the youth QOL in low-cost housing neighbourhood.

\section{Acknowledgement}

This study is made possible by the Longterm Research Grant Scheme (LRGS 2014-0006106-42), Universiti Pendidikan Sultan Idris Perak associated with Universiti Teknologi MARA Shah Alam, and Universiti Putra Malaysia. Special thanks to the supportive supervisor and kindness co-supervisor in supporting the success of this research.

\section{References}

Chiarazzo, V., Coppola, P., Dell'Olio, L., Ibeas, A., \& Ottomanelli, M. (2014). The Effects of Environmental Quality on Residential Choice Location. Procedia - Social and Behavioral Sciences, 162, 178-187. doi:10.1016/j.sbspro.2014.12.198

Crean, H. F. (2012). Youth activity involvement, neighborhood adult support, individual decision making skills, and early adolescent delinquent behaviors: Testing a conceptual model. Journal of Applied Developmental Psychology, 33(4), 175-188. doi:10.1016/j.appdev.2012.04.003

Danis, A., Sidek, S., \& Yusof, S. M. (2014). Environmental Characteristics Influences on Physical Activity among Overweight Adolescents: Urban Neighbourhood Parks. Procedia - Social and Behavioral Sciences, 153, 402-409. doi:10.1016/j.sbspro.2014.10.073

Hashim, A. E., Samikon, S. A., Nasir, N. M., \& Ismail, N. (2012b). Assessing Factors Influencing Performance of Malaysian Low-Cost Public Housing in Sustainable Environment. Procedia - Social and Behavioral Sciences, 50, 920-927. doi:10.1016/j.sbspro.2012.08.093

.Husin, H. N., Nawawi, A. H., Ismail, F., \& Khalil, N. (2015). Correlation Analysis of Occupants' Satisfaction and Safety Performance Level in Low Cost Housing. Procedia - Social and Behavioral Sciences, 168, 238-248. doi:10.1016/j.sbspro.2014.10.229 
Johnston, K., \& Neill, P. O. (2008). Housing Affordability Literature Review and Affordable Housing Program Audit, (July).

Karim, H. A. (2012a). Low Cost Housing Environment: Compromising Quality of Life? Procedia - Social and Behavioral Sciences, 35, 44-53. doi:10.1016/j.sbspro.2012.02.061

Karim, H. A. (2012b). Low Cost Housing Environment: Compromising Quality of Life? Procedia - Social and Behavioral Sciences, 35(December 2011), 44-53. doi:10.1016/j.sbspro.2012.02.061

Keles, R. (2012). The Quality of Life and the Environment. Procedia - Social and Behavioral Sciences, 35, 23-32. doi:10.1016/j.sbspro.2012.02.059

Malone, K. (2002). Street life: youth, culture and competing uses of public space. Environment and Urbanization, 14(2), 157-168. Retrieved from http://eau.sagepub.com/content/14/2/157.short

Okunola, et al. (2012). Perception of Safety, Social Participation and Vulnerability in an Urban Neighbourhood, Lagos, Nigeria. Procedia - Social and Behavioral Sciences, 35, 505-513. doi:10.1016/j.sbspro.2012.02.116

Rachmamarcillia, et al. (2006). Importance of Social Space in Self-built and Donated Post Disaster Housing after Java Earthquake 2006, 25-34.

Rainham, D. G., Bates, C. J., Blanchard, C. M., Dummer, T. J., Kirk, S. F., \& Shearer, C. L. (2012). Spatial classification of youth physical activity patterns. American Journal of Preventive Medicine, 42(5), e87-96. doi:10.1016/j.amepre.2012.02.011

Shuid, S. (2010). Low Income Housing Allocation System in Malaysia : Managing Housing Need for the Poor, 4-7.

Yusop, F. D., \& Sumari, M. (2013). The Use of Social Media Technologies among Malaysian Youth. Procedia Social and Behavioral Sciences, 103, 1204-1209. doi:10.1016/j.sbspro.2013.10.448 